imbalance due to peritoneal irritation which leads to sequestration of fluid, electrolyte and colloid in the adynamic, distended intestine, leading eventually to severe acidosis. The present case is a good example of this electrolyte imbalance, i.e. hyperkalaemia, hypernatraemia, uraemia and acidosis.

This bizarre biochemical picture is a helpful pointer to the diagnosis when an emergency retrograde cystogram cannot be performed or when the clinical picture is not entirely clear, as was the case in the above patient.

\section{Acknowledgments}

I wish to thank Mr A. J. Walton, under whose care the patient was admitted, for his help and encouragement.

\section{References}

BACON, S.K. (1943) Rupture of the urinary bladder. Clinical analysis of 147 cases in the past ten years. Journal of Urology, 40, 432.

Bastable, J.R.G., DE Jode, L.R. \& W ARRen, P. (1964) Spontaneous rupture of the bladder. British Journal of Urology, 31, 78.

Cosbie Ross, J. (1943) Injuries of the urinary bladder. British Journal of Surgery, 32, 44.

Goutier BENIOT, C. (1968) Traumatic intraperitoneal rupture of the bladder with delayed clinical manifestations. Annales de Chirurgie, 22, 1057.

Thompson, I.M. (1965) Bladder rupture. American Archives of Surgery, 90, 371.

\title{
A case of fat embolism following Shiers' arthroplasty
}

\author{
C. H. BRowne \\ M.B., M.R.C.P. \\ Whipps Cross Hospital, London E11
}

\begin{abstract}
Summary
A case of fatal fat embolism following Shiers' replacement arthroplasty of the knee is reported and some of the mechanisms involved discussed.
\end{abstract}

\section{Introduction}

FAT embolism is a recognized complication of Thompson's replacement arthroplasty of the hip using methylmethacrylate cement (Burgess, 1970; Gresham, Kuczynski and Rosborough, 1971; Sevitt, 1972) but has only rarely been reported in association with total knee replacement (Hume Adams et al., 1972; Blum et al., 1974). In a series of 178 Shiers' arthroplasties, Arden (1973) reported three cases of fat embolism. In this case, as in that reported by Harris (1970), hypotension coincided with release of the tourniquet. Fat embolism as a complication of replacement arthroplasty is distinct from the circulatory effects of methylmethacrylate cement.

\section{Case report}

A 65-year-old woman who had suffered from rheumatoid arthritis for 16 years and been chair-

Address for reprints: Cardiothoracic Institute, Brompton Hospital, London, S.W.3. bound for 3 years, was admitted to hospital for an arthroplasty of the right knee. Her pre-operative condition was good, pulse $76 / \mathrm{min}$, regular; blood pressure $140 / 80 \mathrm{mmHg}$; there was no evidence of cardiac failure.

After routine premedication, a Shiers' arthroplasty using methylmethacrylate bone cement to secure the prosthesis, was carried out. Vent holes were not made. A tourniquet was applied for the duration of the operation, which lasted $65 \mathrm{~min}$. On releasing the tourniquet, her blood pressure, which had been well maintained, fell suddenly to $90 \mathrm{mmHg}$ systolic. Her blood pressure was restored to $135 / 90$ $\mathrm{mmHg}$ by infusing $500 \mathrm{ml}$ of dextrose $4 \%$ saline $0 \cdot 18 \%$ solution.

Following reversal of the anaesthetic, she was breathing normally but was unconscious and unresponsive to all painful stimuli. Crepitations and rhonchi were heard throughout both lung fields.

A provisional diagnosis of fat embolism syndrome was made, which was supported by the chest radiograph, which showed widespread patchy shadowing, and the initial blood gas analysis, which showed a $P_{C O}$ of $30 \mathrm{mmHg}$ and a $P O_{2}$ of $47 \mathrm{mmHg}$. The diagnosis was confirmed over the subsequent $48 \mathrm{hr}$ by the appearance of a petechial rash over the trunk 


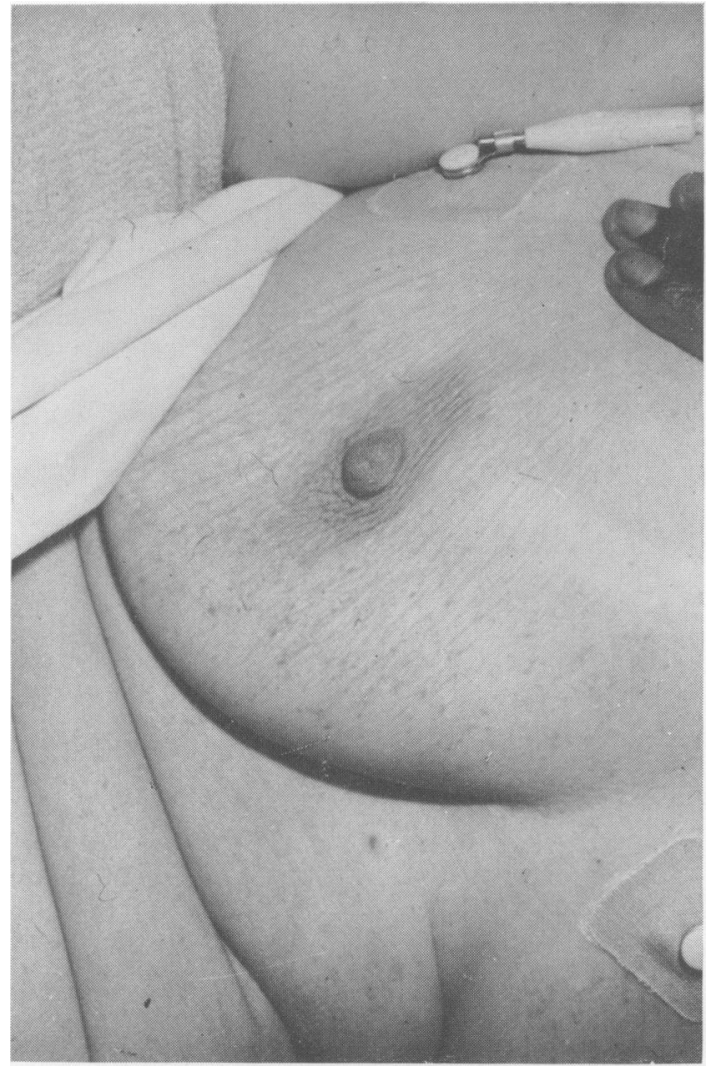

FIG. 1. Typical petechial rash.

(Fig. 1) and boat-shaped haemorrhages in both optic fundi.

Her blood gas values were maintained within normal limits with intermittent positive pressure ventilation; her neurological signs, however, remained unchanged, her general condition deteriorated, and she died 12 days after the operation.

A post-mortem examination confirmed the diagnosis of widespread fat embolism (Figs 2 and 3).

\section{Discussion}

The essential dynamics of fat globule entry into torn vessels is a shift of differential pressure whereby the extravascular pressure rises above that within the vessels. One factor may be the increased quantity of almost liquid fat in the marrow of patients with rheumatoid arthritis (Harris, 1971). The combination of marrow reaming and pressure rise with cement could also be determining factors, since venting the reamed marrow by drill holes or tube has been shown to reduce the raised medullary pressure (Sevitt, 1972; Gresham et al., 1971).

It is recommended that whenever cement and a

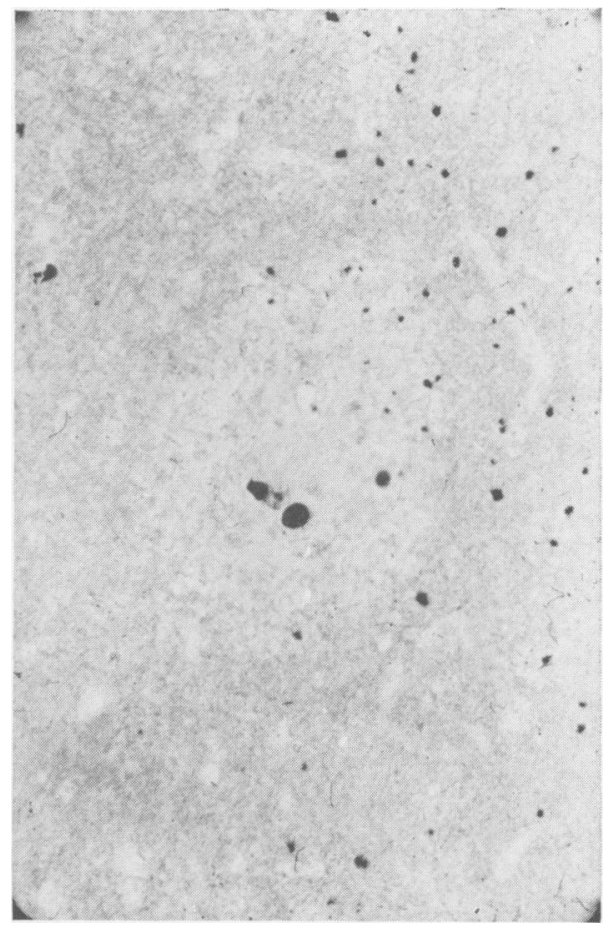

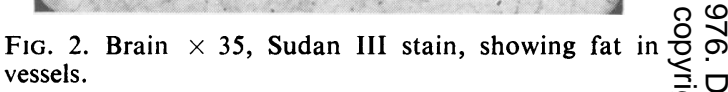

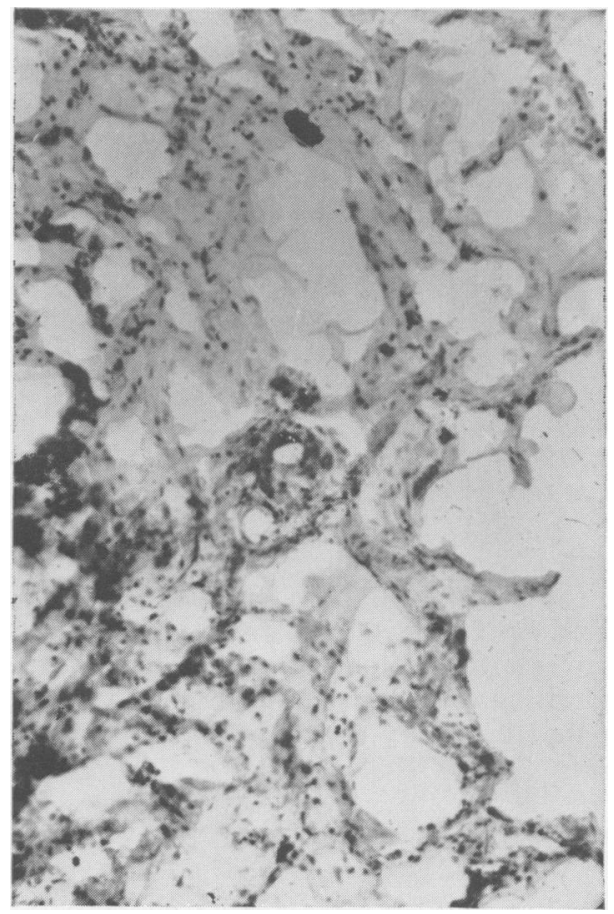

FIG. 3. Lung $\times 35$, Sudan III stain, showing fat in vessels. 
prosthesis are forced into a reamed marrow cavity, drill hole vents should be used to allow excess blood and marrow to escape, thereby avoiding dangerous rises in intramedullary pressure.

Should fat embolism occur, urgent measures should be instituted to maintain blood gas values within normal limits. The place of aprotinin and heparin in treatment is not yet proved, despite earlier promising reports (Gurd, 1969).

\section{Acknowledgments}

I should like to thank Mr D. Richards for permission to report a case under his care, Dr Gillian C. Hanson for help in the preparation of the report, $\mathrm{Dr} \mathrm{C}$. Raeburn for the pathology, and Mrs R. Selby and Mrs J. Snell for secretarial assistance.

\section{References}

Arden, G.P. (1973) Total knee replacement. Clinical Orthopaedics and Related Research, 94, 92.
Blum, B., Mowat, A.G., Bentley, G. \& Morris, J.R. (1974) Knee arthroplasty in patients with rheumatoid arthritis. Annals of Rheumatic Diseases, 33, 1.

Burgess, D.M. (1970) Cardiac arrest and bone cement. British Medical Journal, 3, 588.

Gresham, G.A., Kuczywski, A. \& Rosborough, D. (1971) Fatal fat embolism following replacement arthroplasty for transcervical fractures of femur. British Medical Journal, 2, 617.

GuRD, A.R. (1969) Treatment of fat embolism in experimental animals. In: New Aspects of Trasylol Therapy, p. 151. Schattauer Verlag: Stuttgart 4.

HARRIS, N.H. (1970) Cardiac arrest and bone cement. British Medical Journal, 3, 523.

HaRRIS, N.H. (1971) Fractured femur and fat embolism. British Medical Journal, 3, 47.

Hume Adams, J., Graham, D.I., Mills, E. \& Sprunt, T.G. (1972) Fat embolism and cerebral infarction after use of methylmethacrylate cement. British Medical Journal, 3, 740.

SevitT, S. (1972) Fat embolism in patients with fractured hips. British Medical Journal, 2, 257. 